\title{
97. The Control of Growth and Development in Bombyx mori. XIV
}

\author{
Function of the Corpus Allatum Hormone on the \\ Determination of Molting Characteristics
}

\author{
By Seijiro Morohoshi and Jun Shimada \\ Faculty of Agriculture, Tokyo University of Agriculture and Technology, \\ Fuchu-shi, Tokyo 183
}

(Comm. by Hitoshi KIHARA, M. J. A., June 2, 1972)

It has already been demonstrated that the larval ecdysis is performed by the cooperative action of the corpus allatum and prothoracic gland hormone (Fukuda, 1944), and pupal or adult ecdysis, mainly by the function of the prothoracic gland hormone activated by the brain hormone (Williams, 1959). On the other hand, it was been demonstrated that the number of molts is controlled by a series of allelic major genes on the VI chromosome (Shimodaira, 1947). Then, does the major gene controlling the molting characteristic rule the function of the corpora allata or the function of the prothoracic glands? Morohoshi and Iijima (1969) have demonstrated that ecdysones control larval and pupal ecdysis, and that the control of larval or pupal ecdysis types is due to the activity of the corpus allatum hormone: that is, the activity of the corpus allatum hormone controls the length of time of larval development or the larval molt number.

It was observed by Morohoshi and Kiguchi (unpublished data) that the effect of allatectomy on the feeding activity was very remarkable. The final total amount of dry matter ingested and digested through the 5 th instar in allatectomized larvae which were extirpated just before entering the 4 th molt decreased $(35.70 \mathrm{~g}: 45.97 \mathrm{~g}$ per 20 animals in J. No. $106 \times$ Daizo race) considerably as compared with the controls. The ratio of matter digested through the 5th instar in allatectomized larvae decreased slightly in summer, but there was no such difference in late autumn.

Eggs of the tetramolting and bivoltine strain, J. No. $106 \times$ Daizo, were divided into two groups; one was incubated at $17^{\circ} \mathrm{C}$ in the dark (LD series) and the other at $24^{\circ} \mathrm{C}$ in the light (HL series), and all the hatched larvae were reared at $25^{\circ} \mathrm{C}$.

1. Effect of allatectomy during the 5 th instar larvae of the duration of the subsequent larval and pupal development. Effect of allatectomy during the 5th instar larvae on the duration of the subsequent larval and pupal development was examined. Allatectomy was 


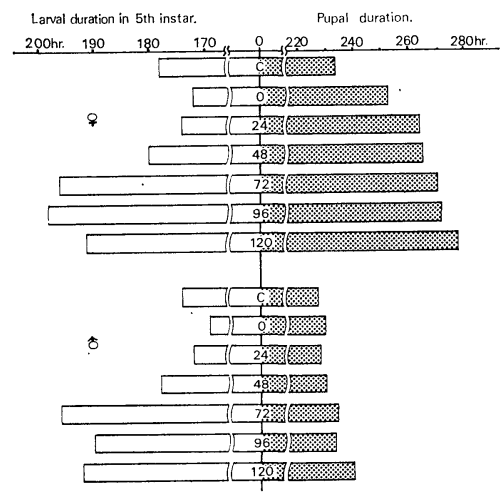

Fig. 1

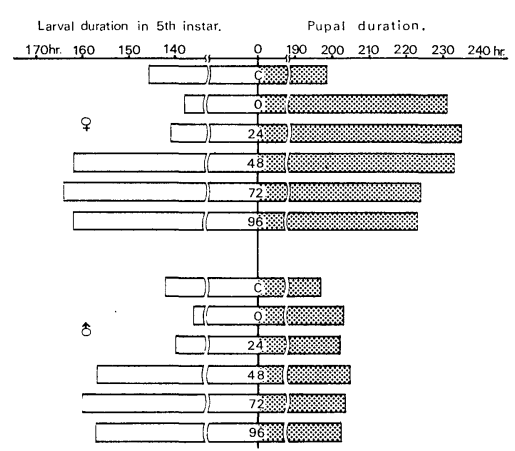

Fig. 2

Fig. 1. Effect of allatectomy during the 5th instar on the subsequent larval and pupal development in the HL series (Average values of 10 animals). C: Control, 0, 24, 48, 72, 96, 120: Allatectomized stage (hr) during the 5th larval instar.

Fig. 2. Effect of allatectomy during the 5th instar on the subsequent larval and pupal development in the LD series (Average values of 10 animals). C: Control, 0, 24, 48, 72, 96: Allatetomized stage (hr) during the 5th larval instar.

carried out immediately, $24,48,72,96$, and 120 hours after the 4 th larval ecdysis. The results were shown in Figs. 1 and 2.

Two striking results were found in both Figs. 1 and 2; one was the duration of larval development, and the other the duration of pupal development. In the former, allatectomy in the early half stage during the 5th instar larvae shortened the duration of the subsequent larval development, and that in the late half stage lengthened subsequent larval duration. Namely, the effect of the corpora allata (CA) on the development of the 5th instar larvae exchanged in the middle stage of the 5th instar. Transplantation of 4 corpora allata or injection of farnesyl-methyl-ether ( $\mathrm{JH})$ in the early half stage during the 5th instar extended the larval duration of the 5th instar as shown in Fig. 3. Akai and Kobayashi (1971) reported a similar result.

In the latter, pupal development by allatectomy during the 5th instar larvae showed different results in males and females; pupal development of females was greatly extended by allatectomy, but that of males was little affected. On the other hand, transplantation of 4 corpora allata to the 5th instar larvae shortened the duration of pupae as shown in Fig. 3. Injection of the $\mathrm{JH}$ into the 5th instar larvae was not always consent with the results of transplantation of the CA. Namely, the injection in the early half stage of the 5th instar lengthened the duration of pupae and the injection in the late half stage shortened it as shown in Fig. 3. The difference of the results in females and males may be due to presence and absence of the ovary. 


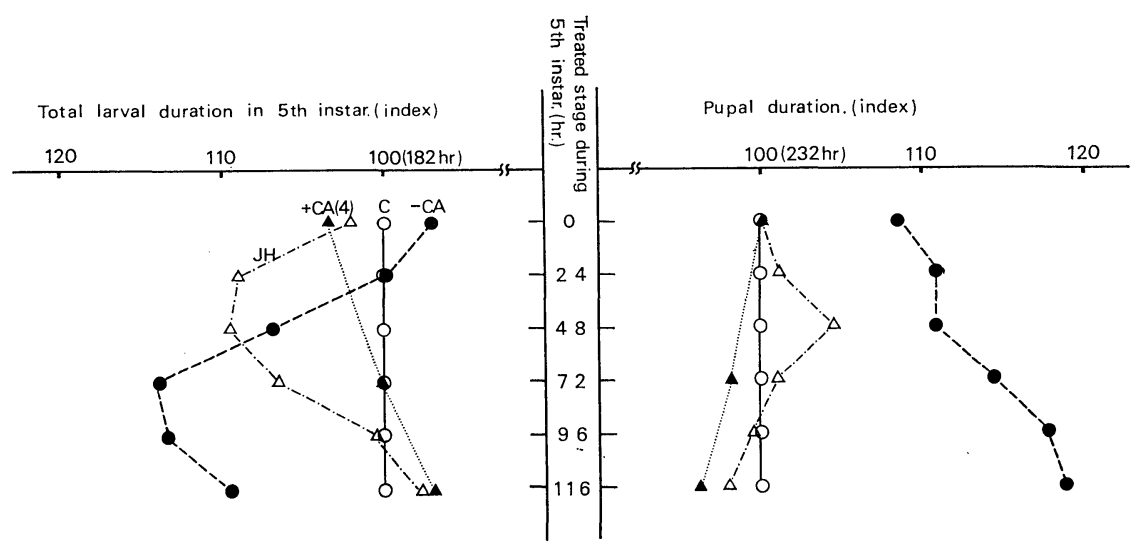

Fig. 3. Effect of the corpora allata (CA) and farnesyl-methyl-ether (JH) during the 5th instar on the subsequent larval and pupal development in the silkworm (average values of 25 animals). C: Control, -CA: Extirpation of CA, +CA(4): Transplantation of 4CA, JH: Injection of $50 \gamma$ farnesyl-methyl-ether.

2. Role of the CA on the determination of molting characteristics. Different races of silkworms are characterized by undergoing 3, 4 and 5 molts during larval life. Although total body is less of weight and silk productions are lower in trimolters than in pentamolters, the duration of each larval instar is longer in trimolters than in pentamolters, especially in the 1st and 2nd stadia. Tetramolters develop at an intermediate rate.

It was already discussed by Morohoshi (1969a) that the activity of the $\mathrm{CA}$ is the strongest in trimolting, intermediate in tetramolting and the weakest in pentamolting. Why does trimolting prolong the length of each instar more than tetramolting or pentamolting? Let us discuss it here from the experimental results of allatectomy. Since the CA weakens the synthesis per hour of protein in the fat body (VII in this series), the synthesis of protein per hour during each larval instar is more active in pentamolting than in tri- or tetramolting. When the synthesis per hour of protein in the early stage during each larval instar is active, the larval instar length is shortened like experimental results of allatectomy in the early half stage during the 5th instar larvae. That is, the duration of each larval instar is shorter in pentamolters in which the activity of the CA is weaker than in tri- or tetramolters as shown in Fig. 4. That is, the CA hormone controls the growth of instar as if gibberellin controls the growth of internode in plants.

3. Relationship between the activity of the CA and prothoracic gland. The relationship between strong and weak activities of the 


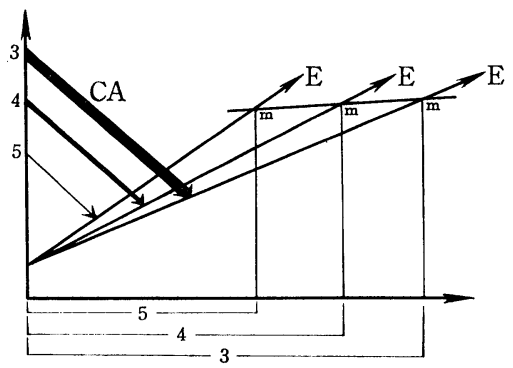

Fig. 4

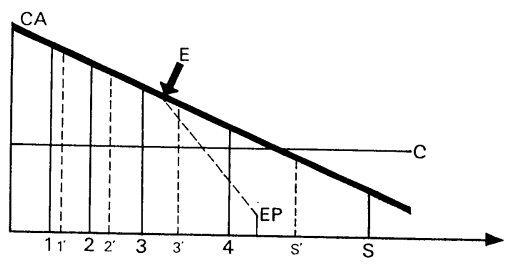

Fig. 5

Fig. 4. Diagram illustrating relationship between the activity of the corpora allata (CA) and the length of same larval instar in 3 strains. Ordinate: Activity of CA, Abscissa: Length of the 1st instar, E: Function of ecdysone, $\mathrm{m}$ : Molting, 3: Trimolting, 4: Tetramolting, 5: Pentamolting strains.

Fig. 5. Diagram illustrating relationship between the activity of the corpora allata (CA) and larval or pupal ecdysis. C: Critical line, 1, 2, 3, 4: Larval ecdysis, S, $\mathrm{S}^{\prime}$ : Pupal ecdysis, EP: Early matured larva or recessive trimolting, $\mathrm{E}$ : Extirpation of corpora allata.

$\mathrm{CA}$ and that between dominant and recessive genes of the molting characteristic are called in question.

The greater the activity of the $\mathrm{CA}$ in the early developmental stage, the shorter the life time and the less the number of molts. It is considered that the dominant gene $\left(M^{3}\right)$ controls the strongest activity of the $\mathrm{CA}$. That is, the activity of the $\mathrm{CA}$ is stronger in trimolting than in tetra- or pentamolting.

There are two types of trimolting races at present; dominant and recessive. The relationship between the activity of the $\mathrm{CA}$ of these races and the prothoracic glands is sketched in Fig. 5.

The dominant trimolting type is a strain in which the activity of the $\mathrm{CA}$ is the strongest and in which it comes below a critical line (C) at the 4th instar (see $1^{\prime}, 2^{\prime}, 3^{\prime}$ and $s^{\prime}$ of broken line in Fig. 5). The recessive trimolting type is a strain in which the activity of the CA is the weakest, and in which it is normal until the 3rd molt and suddenly grows weak at the 4 th instar (see EP in Fig. 5).

4. Effect of the suboesophageal ganglion (SG) hormone on the determination of molting characteristics. It was already demonstrated by Morohoshi (1969b) that the major gene controlling voltinism governs the activity of the SG; the activity of the SG is the strongest in univoltine, intermediate in bivoltine and the weakest in multivoltine silkworms. Although the SG hormone accelerates the accumulation of glycogen and lipid in the ovary, it was demonstrated (Morohoshi, Ohashi and Fugo, 1972) that the SG hormone does not control the length of larval or pupal development. Accordingly, the 
SG hormone is not related to the molting characteristics. Why does the decrease of the number of molts tend to occur in multivoltine or bivoltine races more than in univoltine races? This is considered to be due to the acceleration of the activity of the CA through the nerve commissures of the brain in multivoltine, or bivoltine races incubated at low temperature in the dark.

5. On the determination of molting characteristics. Since the CA hormone is related to protein, lipid and carbohydrate metabolism and controls greatly larval and pupal development, the molting characteristic is mainly determined by the amount of the CA hormone. When silkworms have a large quantity of this hormone, they become trimolters $\left(M^{3}\right)$ and when a small quantity of this hormone, they become pentamolters $\left(M^{5}\right)$. The amount of this hormone is modified by a sex-linked recessive early maturing gene $\left(L \mathrm{~m}^{e}\right)$ controlling the activity of the brain: the recessive early maturing gene stimulates the activity of the CA through nerve commissures from the brain. However, while a large amount of the CA hormone by the stimulation of the brain is released during the early developmental stage, it may be secreted less during the late developmental stage. Accordingly, the stimulation through nerve commissures from the brain may be limited only to early stage (perhaps from late embryonal stage to early larval stage) of development. All multivoltine strains have the $L m^{e}$ gene and "bivoltine silkworms" incubated under the condition of low temperature and darkness have the function of the $L m^{e}$ gene. This brain-corpora allata system $\left(\mathrm{Lm}^{e} \rightarrow \mathrm{CA}\right)$ quickens the larval and pupal development, and changes molting characteristics to a dominant direction $\left(M^{3} \leftarrow+M \leftarrow M^{5}\right)$, and changes voltine characteristics to a recessive direction, $V^{3}$ (multivoltine) $\leftarrow+V$ (bivoltine) $\leftarrow V^{1}$ (univoltine). However, when a large amount of the CA hormone is released into the body fluids under special environmental conditions or by transplantation of the $\mathrm{CA}$ during the late larval stage, this braincorpora allata system lengthens the subsequent larval and pupal development, and changes reversely voltine characteristics to a dominant direction, $V^{3} \rightarrow+V \rightarrow V^{1}$.

Acknowledgement. The authors wish to express their thanks to Dr. Tamura, Department of Agriculture, Tokyo University, Tokyo, Japan, for the offering of this valuable farnesyl-methyl-ether. This investigation was supported by a grant in aid for fundamental scientific research from the Ministry of Education, Japan. 


\section{References}

Akai, H., and Kobayashi, M. (1971): Induction of prolonged larval instar by the juvenile hormone in Bombyx mori L. Appl. Ent. Zool., 6, 138-139.

Fukuda, S. (1944): The hormonal mechanism of larval moulting and metamorphosis in the silkworm. J. Fac. Sci. Tokyo Imp. Univ., 6, 477-532.

Hasegawa, K., and Yamashita, O. (1967): Control of metabolism in the silkworm pupal ovary by the diapause hormone. J. Sericult. Sci. Japan, 36, 297-301.

Kobayashi, M. (1967): An action of insect hormones on carbohydrate metabolism in insects. J. Sericult. Sci. Japan, 36, 302-308.

Morohoshi, S. (1969a): The control of growth and development in Bombyx mori. II. Genic balance in molting characteristics. Proc. Japan Acad., 45, 733-738.

- (1969b): The control of growth and development in Bombyx mori. III. Genic balance in voltinism. Proc. Japan Acad., 45, 739-744.

Morohoshi, S., and Fugo, H. (1971): The control of growth and development in Bombyx mori. X. Effect of the suboesophageal ganglion hormone on the incorporation of ${ }^{14} \mathrm{C}$-glucose into the lipids of the fat body, haemolymph and ovary. Proc. Japan Acad., 47, 416-421.

- (1972): The control of growth and development in Bombyx mori. XI. Effect of the corpus allatum, suboesophageal ganglion, brain and ecdysterone on the incorporation of ${ }^{14} \mathrm{C}-\mathrm{U}$-glucose into pupal fat body and ovary lipids. Proc. Japan Acad., 48, 127-132.

Morohoshi, S., and Iijima, T. (1969): Induction of supernumerous ecdysis by the injection of ecdysterones in Bombyx mori. Proc. Japan Acad., 45, 314-317.

Morohoshi, S., and Kogawara, K. (1971): The control of growth and development in Bombyx mori. VII. Incorporation of ${ }^{14} \mathrm{C}$-leucine into the fat body, haemolymph and ovary proteins in allatectomized pupae. Proc. Japan Acad., 47, 209-214.

Morohoshi, S., Ohashi, F., and Fugo, H. (1972): The control of growth and development in Bombyx mori. XII. Effect of the corpus allatum, suboesophageal ganglion and brain on the incorporation of ${ }^{14} \mathrm{C}-\mathrm{U}$-glucose into pupal fat body and ovary glycogens. Proc. Japan Acad., 48, 258-262.

Morohoshi, S., and Shimada, J. (1971): The control of growth and development in Bombyx mori. VIII. Effect of the corpus allatum, suboesophageal ganglion and brain on the incorporation of ${ }^{14} \mathrm{C}$-leucine into fat body, haemolymph and ovary proteins. Proc. Japan Acad., 47, 319-324.

(1972): The control of growth and development in Bombyx mori. XVI. Effect of the brain and corpora allata on the determination of voltinism. Proc. Japan Acad., 48, 439-444.

Shimodaira, M. (1947): Studies on the linkage inheritance in the silkworm. I. Relation between VI linkage and VIII linkage group. Jap. Jour. Gen., 22, 82-84.

Williams, C. M. (1959): The juvenile hormone. I. Endocrine activity of the corpora allata of the adult Cecropia silkworm. Biol. Woods Hole, 116, 323-338. 